\title{
ENTREVISTA COM SANDRA REGINA CARRIERI DE SOUZA
}

DOI: http://dx.doi.org/10.5965/19843178130220172245

Sandra Regina Carrieri de Souza possui graduação em Pedagogia pela Pontifícia Universidade Católica de São Paulo (1983), pós-graduação em educação e práticas pedagógicas inclusivas e título de mestre em administração universitária pela Universidade Federal de Santa Catarina. Os principais estudos e pesquisas concentramse nas políticas públicas e institucionais de inclusão educacional. Atualmente atua como pedagoga no Museu de Arqueologia e Etnologia Professor Oswaldo Rodrigues Cabral UFSC, onde é uma das responsáveis pela coordenação do setor pedagógico do Museu. Entre as ações pertinentes a essa função, pode-se citar o acolhimento ao público, a elaboração de materiais pedagógicos e de recursos de acessibilidade educacional e informacional, idealização e realização de oficinas, efetivação de parcerias, entre outras.

1) Revista Educação, Artes e Inclusão: Sandra, você é hoje pedagoga do Museu de Arqueologia e Etnologia Professor Oswaldo Rodrigues Cabral, da Universidade Federal de Santa Catarina (MArquE/UFSC) e sabemos que traz para o trabalho no setor pedagógico o olhar de uma vasta experiência na área da inclusão educacional. Gostaria que você começasse nos contando um pouco sobre sua trajetória de formação e atuação profissional...

Sandra Regina Carrieri de Souza: Bom, falar sobre a minha trajetória pode começar pelo meu interesse desde jovem pela área da deficiência, que culminou na escolha por fazer pedagogia na área da deficiência na PUC de São Paulo, universidade que teve o primeiro curso nesta área do Brasil, muito antigo, na época era chamado "Educação para os deficientes da audiocomunicação". Nós trabalhávamos com as pessoas surdas sem usar nenhum tipo de linguagem, inclusive era-nos dito que nós não poderíamos fazer uso de nenhum sinal, para ver como a minha trajetória se inicia num tempo em 
que a educação para as pessoas com deficiência era pensada de uma forma muito diferente de hoje. Dito isso, eu trabalhei na Escola de Surdos em São Paulo, e me afastei por um tempinho bem pequeno, tentando outras coisas. Logo voltei para a Educação Especial, já em Santa Catarina, trabalhando na Fundação Catarinense de Educação Especial, onde eu percebi que a minha grande paixão não era pela área da surdez, mas pela da deficiência intelectual e pelo transtorno do espectro autista (TEA), que sempre me fascinou. Para mim sempre foi um grande desafio - e é, até hoje: muitas vezes ainda sinto que falta aprender muita coisa para lidar com esses sujeitos, de uma forma que seja adequada, que seja significativa para eles e para mim enquanto profissional. Trabalhei nas APAEs, cedida pelo Estado, pela Fundação Catarinense, até que eu passei em um concurso em Biguaçu (SC) como segunda professora e ao mesmo tempo como pedagoga da Educação Especial na Universidade Federal de Santa Catarina, para o Colégio de Aplicação, onde eu atuei por oito anos. Ali eu vi se fechar um ciclo e vi também que eu tinha que procurar novos desafios. Foi assim que eu cheguei ao Museu, que foi uma surpresa muito positiva, porque sempre me ficou a dúvida de como eu poderia aplicar a minha experiência e a minha paixão pela deficiência em um lugar tão diferente e do qual eu não tinha conhecimento nenhum a respeito - que era a área museológica. Hoje eu vejo que é exatamente isto que tem que permear a Educação Especial: ele [o sujeito com deficiência] não deve estar recluso dentro de uma escola, de quatro paredes. A inclusão educacional tem que combater a exclusão que se tem em todas as áreas, não só a educacional, e levando-se em conta toda a diversidade. Então em todos os locais eu acho que deveria haver profissionais, não necessariamente da área da pedagogia, da educação especial, mas que estejam preocupados em acolher a diversidade. E é isso que nós procuramos fazer no Museu, não só eu como minha colega de trabalho: o que a gente faz na verdade é tentar acolher a diversidade. De que forma? Dando ferramentas para que as pessoas se sintam pertencentes ao espaço museal.

\section{2) Revista Educação, Artes e Inclusão: E quais desafios você considera principais para a efetivação desse acolhimento no espaço museal?}


Sandra Regina Carrieri de Souza: Eu acho que não só no espaço museal, mas em todos os espaços, são as barreiras atitudinais. Você pode ter um piso podotátil para um cego, você pode ter LIBRAS para uma pessoa surda... se não tiver uma atitude de acolhimento, de respeito, de entender que somos iguais e que aquela é só uma característica [do sujeito], tudo se perde. Penso que em qualquer espaço o grande desafio continua sendo esse. Sem desconsiderar, lógico, na situação em que o país se encontra, as dificuldades que temos tido para eliminar as outras barreiras: para minimizar as barreiras comunicacionais, as barreiras pedagógicas, precisa-se de incentivo público, de políticas públicas. Mas para mim, o carro chefe de tudo é a eliminação da barreira atitudinal. Enquanto a gente não entender a questão da deficiência como algo ligado a direitos humanos, eu acho que nada acontece.

\section{3) Revista Educação, Artes e Inclusão: O que vocês vêm conseguindo efetivar no} Museu em termos de inclusão, como você vê esse trabalho sendo efetivado?

Sandra Regina Carrieri de Souza: No Museu... para mim foi um aprendizado muito grande porque eu tive que reeducar o meu olhar. Reeducar o meu olhar no sentido de como eu vejo o meu próprio trabalho. Porque você sempre acha que está fazendo muito pouco pela questão da deficiência. E aí quando você vê os outros espaços, as dificuldades que os outros espaços, embora tentem, também estão tendo; quando você vê o que você consegue alcançar com uma atitude super pequena, que você consegue um resultado bacana, você começa a reeducar o seu olhar. De que você tem que ir passo a passo. Eu acho que é isso que a gente está fazendo. E eu acho que a gente está fazendo no Museu uma coisa muito importante, que é: a gente está conseguindo abrir o olhar do outro para a questão da deficiência no espaço. Por exemplo: numa exposição de rendas nós fizemos adequações em que as pessoas cegas podiam ter acesso a reproduções de rendas em papel [protótipos táteis], e na verdade nós quase não tivemos pessoas cegas que utilizassem isto, mas as outras crianças, os outros públicos que vieram começaram a 
perceber que o público cego faz parte desse espaço, e que ele faz parte de qualquer espaço. Então a gente está conseguindo, além de fazer adequações para as pessoas com deficiências, sensibilizar as pessoas sem deficiências para as necessidades das pessoas com deficiências, ou seja, a gente está abrindo os olhos para a diversidade.

4) Revista Educação, Artes e Inclusão: Sandra, você nos falou também de uma vasta atuação na Educação Básica. Como você vê a inclusão nesses espaços? Quais são os maiores desafios na sua opinião?

Sandra Regina Carrieri de Souza: Olha, eu vou ser repetitiva e falar de novo que é a barreira atitudinal. E você vai me perguntar: "por parte dos alunos?" - geralmente quando eu falo isso as pessoas perguntam “ai, são os alunos? Eles rejeitam?”. Não. São raras as vezes em um espaço educacional do ensino básico que você vê a questão do aluno rejeitando o outro; você vê aquelas questões comuns em qualquer espaço educacional, mas nada específico por ser um aluno com deficiência. O que você vê são os adultos. E nos adultos eu incluo alguns pais de alunos, e eu incluo principalmente alguns professores. Quando eu falo alguns é para frisar bem que eu não quero generalizar. Existe um pessoal fazendo um trabalho incrível, com pouquíssimo recurso, e a gente não pode colocar todo mundo no mesmo saco. Mas ainda existe barreira atitudinal em todas as áreas, inclusive no Ensino Superior. Na minha dissertação eu trabalhei com a questão do Ensino Superior, do acolhimento e das políticas públicas para o aluno da graduação e da pós-graduação. E você vê professores que sentem que, usando palavras deles, "não são pagos para isso", para acolher essa diversidade. O discurso do "não estou preparado" permeia a questão da Educação Especial e da Inclusão Educacional até hoje. Então a gente está lidando fortemente com essas questões desde os anos 1990 e as pessoas não estão preparadas. Estão esperando o quê para se preparar? Tudo bem: não tem política pública para preparar o professor. Mas aqui na UFSC [Universidade Federal de Santa Catarina] tem, e mesmo assim a gente ouve. Outros espaços também estão tentando fazer, só que tem que ter uma busca 
pessoal também: se eu não quero, se eu não busco, a coisa não vem até mim. Então eu sinto que o que falta é isso: é a busca, é o acolhimento, e principalmente acreditar no potencial daquele alunado. Se você olha para aquele aluno e acha que não vai ser possível, daí não adianta tecnologia, não adianta nada... -Vejo que existem professores que têm um olhar muito bonito, sabendo que é possível. E primeiro: o que é importante para esse aluno aprender? Vamos conversar com as famílias, vamos sentir esse aluno, vamos adequar o que é importante para a vida dele - e não ficar com expectativas que fazem a gente achar que se o sujeito não aprendeu aquele exercício de matemática dificílimo do outro aluno ele não aprendeu nada. Então é preciso mudar também os parâmetros com que se ensina e com que se avalia essa ensinagem, porque senão a gente sempre vai achar que não fez nada, e que o aluno não fez nada... então a gente realmente precisa reeducar o olhar quando lida com esse público. Eu foquei bastante na minha dissertação em distúrbios de aprendizagem e não em deficiência, porque o distúrbio de aprendizagem fica num buraco negro, parece que ninguém é responsável por ele, o profissional de Educação Especial não é responsável por ele, o professor por sua vez não está preparado para lidar com ele, o aluno às vezes também não se coloca, a família também não se coloca... e o que acontece? Ele fica invisível. Então a minha grande preocupação tanto na dissertação quanto na atuação no Colégio de Aplicação foi acolher as pessoas com distúrbio de aprendizagem, porque chega a ser desumano. Essas pessoas ficam na invisibilidade, e quando você fica na invisibilidade, quando não se expõe... e isso vale também para a deficiência: quando não se expõe a deficiência ou o distúrbio você pode rotular de tantas outras coisas que não são reais, como falta de vontade, como a família que erra, milhões de coisas, "isso é falta de educação e não um problema”... Quando na verdade por trás de um distúrbio de aprendizagem existe um fator neurológico, que tem que ser levado em consideração. Eu gostaria de falar um pouco sobre a questão diagnóstica, porque hoje se fala muito: "não se pode trabalhar visando e focando no diagnóstico", mas o diagnóstico é superimportante como ponto de partida. Se você não conhece aquele aluno, é lógico que você não vai conhecer só pelo diagnóstico: você vai ter que fazer uma anamnese com família, com tudo, você vai fazer uma observação cuidadosa... mas se você não tiver um diagnóstico inicial, você não 
consegue. Então na questão dos distúrbios acaba se esquecendo dessa causa neurológica, que vai permear todo processo de ensino e aprendizagem.

5) Revista Educação, Artes e Inclusão: Sandra, voltando um pouco para o museu. A gente falou das pessoas com deficiência, mas sabemos que vocês têm um projeto para ampliação de públicos, para outras tipologias de público. Você poderia falar um pouco sobre isso?

Sandra Regina Carrieri de Souza: Sim, eu acho que vai ao encontro do que eu já falei. A questão da deficiência não pode ser vista isoladamente e nem a inclusão como só a questão da inclusão educacional, é uma questão de direitos humanos e acolhimento à diversidade. Então estamos falando de algo muito mais amplo e muito sério, que é a exclusão social. Quando pensamos em um trabalho no museu, um trabalho educativo, pedagógico, no museu, o que a gente vai pensar? Em como a gente vai acolher essa diversidade. Em como a gente vai tentar sanear, o mínimo que seja, a questão da exclusão social. Então quando você amplia o seu público, quando você acolhe os idosos, acolhe as pessoas com deficiência, acolhe os reeducandos do sistema prisional, acolhe pessoas com pouca instrução adequando a linguagem, dentre tantos outros grupos, pessoas falantes de outras línguas... Você está diminuindo a exclusão social, que hoje não acontece só com a pessoa com deficiência. A exclusão social é muito forte no nosso país, então a gente tem que ver isso de uma forma mais ampla e é isso que se pretende quando tentamos ampliar os públicos. Eu posso dizer para você que é super gratificante, você tem respostas que não imaginava quando as pessoas são bem acolhidas. E a gente faz questão de mostrar que isso não é um favor, é um direito. Eu acho que essa questão tem que permear todas as nossas ações pedagógicas: não fazer com que a pessoa se sinta recebendo um favor - é uma obrigação de quem trabalha com educação fazer esse acolhimento, fazer as adequações que permitam que essa pessoa se sinta acolhida. Você consegue avaliar que conseguiu acolher exatamente pela forma 
como a pessoa reage e isso é extremamente gratificante para quem está atuando como profissional.

6) Revista Educação, Artes e Inclusão: Para terminar, você tem alguma mensagem que queira deixar, algum comentário final?

Sandra Regina Carrieri de Souza: Eu só queria dizer que para quem trabalha com Educação Especial, com a área da deficiência ou está focando na área da inclusão social, é importante estar estudando sempre, porque isso está sempre em movimento, os grupos vão surgindo, a gente hoje tem uma questão de gênero também que a gente precisa trabalhar com muito cuidado, com muito respeito. Então a gente tem que estar o tempo todo tentando acompanhar esse movimento, estudando, participando de grupo de pesquisa, tentando escrever... É logico que às vezes conciliar isso com o nosso trabalho fica um pouco difícil, mas eu acho superimportante. Então o recado é esse, para quem está começando e para quem está mais para lá do final da linha como eu: que a gente continue se apaixonando e tendo esses momentos de buscar saber algo mais que possa contribuir para a questão de acolhimento à diversidade. 